\title{
Processing of Al-12Si-TNM composites by selective laser melting and evaluation of compressive and wear properties
}

\author{
Konda G. Prashanth ${ }^{\text {a),b) }}$ and Sergio Scudino \\ IFW Dresden, Institute for Complex Materials, D-01171 Dresden, Saxony, Germany \\ Anil K. Chaubey \\ Institute of Minerals and Materials Technology (IMMT), Bhubaneshwar - 751013, Orissa, India \\ Lukas Löber ${ }^{\mathrm{c})}$ and Pei Wang \\ IFW Dresden, Institute for Complex Materials, D-01171 Dresden, Saxony, Germany \\ Hooyar Attar \\ IFW Dresden, Institute for Complex Materials, D-01171 Dresden, Saxony, Germany; and School of Engineering, \\ Edith Cowan University, Perth, Western Australia 6027, Australia
}

Frank P. Schimansky and Florian Pyczak

Helmholtz-Zentrum Geesthacht, D-21502 Geestacht, Germany

Jürgen Eckert ${ }^{\mathrm{d})}$

Erich Schmid Institute of Materials Science, Austrian Academy of Sciences, Jahnstraße 12, A-8700 Leoben, Austria; and Department of Materials Physics, Montanuniversität Leoben, Jahnstraße 12, A-8700 Leoben, Austria

(Received 19 August 2015; accepted 5 October 2015)

\begin{abstract}
Al-12Si (80 vol\%)- $\mathrm{Ti}_{52.4} \mathrm{Al}_{42.2} \mathrm{Nb}_{4.4} \mathrm{Mo}_{0.9} \mathrm{~B}_{0.06}$ (at.\%) (TNM) composites were successfully produced by the selective laser melting (SLM). Detailed structural and microstructural analysis shows the formation of the $\mathrm{Al}_{6} \mathrm{MoTi}$ intermetallic phase due to the reaction of the TNM reinforcement with the Al-12Si matrix during SLM. Compression tests reveal that the composites exhibit significantly improved properties $(\sim 140$ and $\sim 160 \mathrm{MPa}$ higher yield and ultimate compressive strengths, respectively) compared with the $\mathrm{Al}-12 \mathrm{Si}$ matrix. However, the samples break at $\sim 6 \%$ total strain under compression, thus showing a reduced plasticity of the composites. Sliding wear tests were carried out for both the Al-12Si matrix and the Al-12Si-TNM composites. The composites perform better under sliding wear conditions and the wear rate increases with increasing loads. At high loads, the wear takes place at three different rates and the wear rate decreases with increasing experiment duration.
\end{abstract}

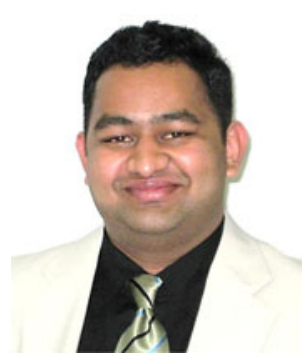

Konda G. Prashanth
I, Dr.-Ing. Prashanth Konda Gokuldoss (K.G. Prashanth) started my career in Bachelors of Engineering (B.E.) in Metallurgical Engineering (2002-2006) followed by Master of Technology (M.Tech.) in Metallurgical and Materials Engineering from the Indian Institute of Technology_Madras, India (2006-2008). During my M.Tech. I got the opportunity to carry out M.Tech. dissertation at the Leibniz Institute for Solid State and Materials Research, Dresden, Germany as an exchange student through scholarship from German Academic Exchange Service (DAAD—Deutscher Akademischer Austauschdienst). The next two years and half I was associated with the Helmholtz Center Berlin for Materials and Energy, Berlin, Germany where I was working on nano-composites and metallic foams. I had started my Ph.D. (late 2011) in the field of additive manufacturing (Selective Laser Melting-SLM) at the Leibniz Institute for Solid State and Materials Research, Dresden, Germany. Having received my doctorate (Dr.-Ing.) in May 2014, I continued as a Post-doctoral researcher until February 2015 at the same institute. Since March 2015, I am employed at Sandvik AB, (Sandviken, Sweden) Group: Additive Manufacturing as a R\&D Engineer.
Contributing Editor: Yang-T. Cheng

a) Address all correspondence to this author.

e-mail: kgprashanth@gmail.com

${ }^{b}$ Present Address: R\&D Engineer, Additive Manufacturing Center, Sandvik AB, 81181 Sandviken, Sweden; e-mail: prashanth.k_g@sandvik.com

${ }^{c}$ Present Address: R\&D Engineer, Sauer GmbH-DMG MORI SEIKI, D-87459 Pfronten, Germany

${ }^{\mathrm{d})}$ This author was an editor of this journal during the review and decision stage. For the $J M R$ policy on review and publication of manuscripts authored by editors, please refer to http://www.mrs.org/jmr-editor-manuscripts/.

A previous error in this article has been corrected, see 10.1557/jmr.2016.15.

DOI: $10.1557 / \mathrm{jmr} .2015 .326$

\section{INTRODUCTION}

Selective laser melting (SLM) is one of the powder-based additive manufacturing techniques used to produce three dimensional near-net shaped components with superior properties layer by layer. ${ }^{1-4}$ As the name suggests, a laser source(s) is used to melt the powder layers selectively as dictated by a computer model (generally a computer aided design - CAD file or a computed tomogram-3D CT scan). The SLM process offers a high degree of freedom and theoretically parts with any geometry (complex shapes and 
structures) and can be produced without restrictions, which are otherwise difficult or nearly impossible to produce using conventional manufacturing processes. ${ }^{5-8}$ This process is also believed to lower the production time of complex parts, to maximize material utilization, and is considered to be environmentally friendly. ${ }^{9}$

Most of the SLM research is focused on the following alloys: (i) pure iron, stainless steel, and different tool steel grades in the directions of parameter optimization, structure optimization, and evaluation of mechanical properties $^{10-13}$; (ii) Al-based alloys, like $\mathrm{Al}-12 \mathrm{Si}$ and AlSi10Mg, mainly focused on parameter optimization and evaluation of various properties ${ }^{14-16}$ (iii) Ti6Al4V (for high strength aerospace applications), pure titanium and beta titanium alloys (bulk and porous scaffolds for bio-medical applications) focusing on the parameter optimization and evaluation of related bio-medical, corrosion and mechanical properties ${ }^{17-20}$; (iv) Ni-based alloys like nitinol, inconels, and waspaloys (for high temperature properties and shape memory effects) mainly focused on parameter optimization and high temperature properties $^{21-24}$ and (v) Co-based alloys (CoCrMo as dental implants) focused on the microstructure and biomedical properties. ${ }^{25,26}$ Altogether, the majority of the research shows that parts produced by SLM have improved properties compared to parts produced by conventional casting/powder metallurgy techniques. ${ }^{14,15}$

Several attempts were made to further improve the properties (mechanical, tribological, and bio-medical) of SLM produced parts by adding reinforcing particles to the metal matrix. For example, Song et al. added hard $\mathrm{SiC}$ to pure $\mathrm{Fe}$-powder to improve the mechanical properties of the iron matrix produced by SLM. ${ }^{27}$ Similarly, Hao et al. and Wei et al. produced hydroxyapatite reinforced steel composites by SLM. ${ }^{28,29}$ Even though the motivation of mixing hydroxyapatite with stainless steel is for biomedical applications, the reports show a detailed microstructural analysis and mechanical properties evaluation of these composites. Ti-based alloys are extensively used as a matrix for the SLM based composites for improved mechanical and biomedical properties. For example, Attar et al. have produced $\mathrm{Ti}-\mathrm{TiB}$ composites and lattice structures for biomedical applications. ${ }^{6,30}$ The phase formation of $\mathrm{Ti}-$ TiB composites was studied in detail and the mechanical properties were evaluated. ${ }^{6,30}$ It has been observed that the $\mathrm{TiB}$ reinforcement reacts with the $\mathrm{Ti}$ matrix and results in an additional phase, which may be regarded as beneficial. There are also reports, where ceramic TiC and graphite are added to Ti-based matrices for producing composites using SLM. ${ }^{31-33}$ The TiC reinforced composites were evaluated for both mechanical and tribological properties. ${ }^{31-33}$ They also revealed a reaction between the reinforcement and the matrix during the SLM process.
An Al-based matrix like $\mathrm{AlSi} 10 \mathrm{Mg}$ is used in conjunction with both $\mathrm{SiC}$ and $\mathrm{TiC}$ reinforcements for the production of composites using SLM. ${ }^{34,35}$ Dadbakhsh et al. have demonstrated the use of $\mathrm{Fe}_{2} \mathrm{O}_{3}$ as reinforcement with pure aluminum as a matrix. ${ }^{36}$ They worked on the optimization of processing parameters and evaluated the mechanical properties of the resultant composites. ${ }^{36}$ With the available reports on the production of composites by the SLM process some common facts can be observed: (i) most of the reinforcements used are nonmetallic (ceramic) in nature, like $\mathrm{SiC}, \mathrm{TiC}$, and $\mathrm{Fe}_{2} \mathrm{O}_{3}$, (ii) in most of the cases there is a reaction between the reinforcement and the matrix during the SLM process and (iii) the composite approach leads to an improvement of the mechanical (strength at the expense of ductility) and tribological properties, however rendering the material more brittle than the unreinforced matrix. On the other hand, there are no reports available that deal with composites with metallic reinforcements. It would be of significant interest for applications in the aerospace sector, to evaluate a composite with metallic reinforcement because it may limit the brittleness of the resultant composite. In addition, there may be a reaction between the metal matrix and the metallic reinforcement which may improve the bonding between the matrix and the reinforcement, resulting in improved properties.

Hence, the present work focuses on the production of $\mathrm{Al}-12 \mathrm{Si}-\mathrm{Ti}_{52.4} \mathrm{Al}_{42.2} \mathrm{Nb}_{4.4} \mathrm{Mo}_{0.9} \mathrm{~B}_{0.06}$ (at.\%) (TNM) composites produced by SLM. TNM is metallic and it may lead to better compatibility with the unreinforced $\mathrm{Al}-12 \mathrm{Si}$ matrix than ceramic reinforcements like $\mathrm{SiC}$ and $\mathrm{Fe}_{2} \mathrm{O}_{3}$. Wang et al. have produced $\mathrm{Al}-12 \mathrm{Si}-\mathrm{TNM}$ composites (TNMCs) by conventional powder metallurgy route through hot pressing and hot extrusion. ${ }^{37}$ However, there is no melting involved in the powder metallurgy process; the phases observed should be significantly different and in turn the mechanical properties. The structural and microstructural aspects of the composites produced by SLM are analyzed in detail and are compared with the $\mathrm{Al}-12 \mathrm{Si}$ samples produced to evaluate the differences and to understand the phase formation in the Al-12Si-TNM SLM composites. Both the $\mathrm{Al}-12 \mathrm{Si}-\mathrm{TNMCs}$ and unreinforced $\mathrm{Al}-12 \mathrm{Si}$ matrix are tested for hardness, uniaxial compression, and sliding wear. A decisive mechanism for both phase formation and wear is proposed for the Al-12Si-TNM SLM composites.

\section{EXPERIMENTAL}

Al-12Si (wt $\%$ ) with an average particle size of $34 \pm 5 \mu \mathrm{m}$ and TNM powders with an average particle size of $41 \pm 5 \mu \mathrm{m}$ were produced by gas atomization. ${ }^{38}$ Mixtures of $80 \mathrm{vol} \%$ of $\mathrm{Al}-12 \mathrm{Si}$ and $20 \mathrm{vol} \%$ of TNM gas atomized powders (GAP) were prepared by room temperature mechanical 
milling using a Retsch PM400 planetary ball mill (Haan, Germany) to have a Al-12Si-TNMC with a homogeneous distribution of reinforcement in the matrix. The milling was carried out for $2 \mathrm{~h}$ with hardened steel balls and vials with a rotational speed of 100 rotations per minute (rpm) and a ball to powder ratio of 10:1. Such gentle milling conditions are used in the present study unlike $^{39}$ in order have gentle mixing between the matrix and the reinforcement and to avoid any possible deformation of the powder. Bulk specimens $(4 \mathrm{~mm}$ diameter, $20 \mathrm{~mm}$ height) of both unreinforced $\mathrm{Al}-12 \mathrm{Si}$ matrix and TNMC were produced by SLM at room temperature using a SLM $250 \mathrm{HL}$ device (from SLM Solutions, Lübeck, Germany) equipped with an Yb-YAG laser. The following parameters were used to prepare Al12Si and TNMC: a laser power of $320 \mathrm{~W}$, volume and contour scanning speeds: $1455 \mathrm{~mm} / \mathrm{s}$ for the volume speed and $1939 \mathrm{~mm} / \mathrm{s}$ for the contour speed, a layer thickness of $50 \mu \mathrm{m}$ and a hatch spacing of $110 \mu \mathrm{m}$ with a hatch style rotation of $73^{\circ}$. Support structures were built between the samples and the substrate plate for easy removal of the samples from the substrate plate. The samples were built under argon atmosphere with an oxygen content $<0.2 \mathrm{wt} \%$ in the building chamber to minimize oxidation during the building process.

Structural analysis was performed in Bragg-Brentano configuration by x-ray diffraction (XRD) using a D3290 PANalytical X'pert PRO (Kassel-Waldau, Germany) with $\mathrm{Co}-\mathrm{K}_{\alpha}$ radiation $(\lambda=0.17889 \mathrm{~nm})$. The Rietveld method was applied for the profile fitting structural refinement using the WinPlotR software package (Rennes, France). The density of the consolidated SLM samples was evaluated by using the Archimedes principle (Sartorius AG, Göttingen, Germany). Distilled water was used as the liquid medium to measure the density. All specimens for density measurements were tested at least three times, and the average density of each specimen was calculated.

The microstructural characterization was carried out by optical microscopy using a Zeiss Axioskope 40 (NeuIsenburg, Germany). Scanning electron microscopy (SEM) was performed using a Gemini 1530 microscope (Göttingen, Germany), which is also equipped with an energy dispersive x-ray spectroscopy (EDX) setup. Compression tests (sample dimensions: $4 \mathrm{~mm}$ diameter and 8 $\mathrm{mm}$ height) were carried out at room temperature using an Instron 8562 (Darmstadt, Germany) testing facility under quasistatic loading with a strain rate of $10^{-4} \mathrm{~s}^{-1}$. The strain during the compression tests was measured directly on the specimen using a Fiedler laser-extensometer (Lützen, Germany). The Vickers microhardness of the samples was evaluated according to the ASTM standard: E384-11e1 with a typical pyramid diamond indenter using a computer controlled HMV Schimadzu microhardness testing machine (Dusiburg, Germany) with an applied load of $0.1 \mathrm{~N}$ and a dwelling time of $10 \mathrm{~s}$.
Room temperature sliding wear tests were carried out according to the ASTM standards ASTM G 99-05 in an ambient atmosphere using a pin-on-disc test device (TR 2HT M3 device from DUCOM Instruments, Bengaluru, Karnataka, India). A disc of $80 \mathrm{~mm}$ diameter and $13 \mathrm{~mm}$ thickness made of hard-faced stainless steel was used against the $\mathrm{Al}-12 \mathrm{Si}$ composite flat head pins of 4 $\mathrm{mm}$ diameter and $20 \mathrm{~mm}$ height. The tests performed were a function of loads varying from 10 to $50 \mathrm{~N}(10,20$, 30,40 , and $50 \mathrm{~N}$ ). A sliding speed of $1 \mathrm{~m} / \mathrm{s}$ was used for $30 \mathrm{~min}$. The wear rate was evaluated by ${ }^{40}$

$$
Q_{\mathrm{s}}=\frac{V_{\mathrm{s}}}{L_{\mathrm{s}}}
$$

where $Q_{\mathrm{s}}$ corresponds to the wear rate, $L_{\mathrm{s}}$ the sliding distance, and $V_{\mathrm{s}}$ the sliding volume loss. The subscript s indicates that the wear measurements were carried out in sliding mode. The volume loss $V_{\mathrm{s}}$ can be expressed by the Archard equation as ${ }^{41}$

$$
V_{\mathrm{s}}=\frac{k W L_{\mathrm{s}}}{H}
$$

where $k$ corresponds to the wear coefficient, $W$ is the applied load, and $H$ is the hardness of the material. The volume loss of the material was calculated from the wear loss determined by measuring the weight of the flat head pins before and after the wear tests. The sliding distance is calculated using the equation: $L_{\mathrm{s}}=2 \pi r_{\mathrm{s}} v_{\mathrm{s}} t_{\mathrm{s}}$, where $r_{\mathrm{s}}$ corresponds to the radius of the wear track $(40 \mathrm{~mm}), v_{\mathrm{s}}$ is the speed expressed in rpm, and $t_{\mathrm{s}}$ is the time used for the wear test $(30 \mathrm{~min})$.

\section{RESULTS}

\section{A. Structural and microstructural analysis}

The XRD patterns of the gas-atomized $\mathrm{Al}-12 \mathrm{Si}$ and TNM powders along with the $\mathrm{Al}-12 \mathrm{Si}$ and TNMC with 20 vol\% TNM SLM samples are shown in Fig. 1. The $\mathrm{Al}-12 \mathrm{Si}$ GAP shows diffraction peaks of $\alpha$-Al [face centered cubic structure, Pearson symbol: $c F 4$, and space group: $F m 3 m$ (Ref. 42)] whereas the peaks of Si are not distinctly visible. The TNM powder shows the presence of the following intermetallic phases: $\mathrm{AlTi}_{3}$ [hexagonal structure, Pearson symbol: $h P 8$, and space group: P63/ $m m c$ (Ref. 43)] and MoNb [body centered cubic structure, Pearson symbol: $c l 2$, and space group: $\operatorname{Im} 3 m$ (Ref. 44)]. The Al-12Si SLM samples display the crystalline peaks of $\alpha-\mathrm{Al}$ along with weak Si peaks, similar as those observed for the $\mathrm{Al}-12 \mathrm{Si}$ powder. However, the intensities of the $\alpha$-Al peaks (111) and (200) are reversed with respect to the $\mathrm{Al}-12 \mathrm{Si}$ powder. The XRD pattern of the Al12-Si-TNM SLM sample shows the presence of $\alpha$-Al peaks and the peaks of $\mathrm{Si}$ are weak. The Si peaks are not 
as distinct as in the case of the Al-12Si SLM samples. However, in contrast to the Al-12Si SLM sample, there is no texture observed between the $\alpha$-Al peaks (111) and (200). Additional peaks from the $\mathrm{Al}_{6} \mathrm{MoTi}$ phase [orthorhombic structure, Pearson symbol: $o C 112$, and space group: $C m c 2_{1}$ (Ref. 45)] are also observed.

The microstructure of both the unreinforced $\mathrm{Al}-12 \mathrm{Si}$ and the TNMC composites prepared by SLM are shown in Fig. 2. The low magnification SEM images [Figs. 2(a) and 2(b)] of the Al-12Si SLM samples do not reveal any characteristics except for the nonuniformity in the microstructure and the laser tracks or track overlaps [Fig. 2(a)]. Track overlaps are the regions, where the melting takes place twice between two laser tracks. At higher magnification [Fig. 2(c)] the Al-12Si SLM sample displays a cellular microstructure (cell size varying between

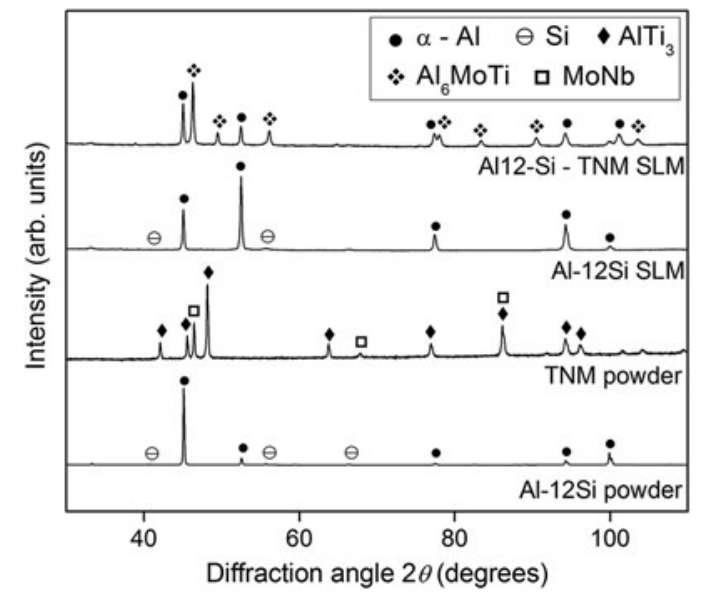

FIG. 1. XRD patterns $(\lambda=0.17889 \mathrm{~nm})$ of the Al-12Si and TNM powders and the unreinforced $\mathrm{Al}-12 \mathrm{Si}$ and $\mathrm{Al}-12 \mathrm{Si}-20$ vol\% TNMC samples produced by SLM.
500-1000 nm) with the Si phase present along the cellular boundaries (thickness $\sim 200 \mathrm{~nm}$ ). ${ }^{14}$ Moreover, the microstructure is nonuniform with an elongated morphology along the track overlaps and circular morphology outside of the track overlaps. ${ }^{14}$ Such an anisotropic structure is a characteristic for SLM samples. ${ }^{46-48}$ On the other hand, the microstructure of the TNMC is completely different. Figures 2 (d)-2(f) suggest that the reinforcement is distributed in the form of irregularly shaped dendrites and particles, with an average width of $482 \pm 68 \mathrm{~nm}$ and $1.75 \pm 0.32 \mu \mathrm{m}$ length. It can also be observed that the distribution of the reinforcement is not uniform throughout the sample, with a coarser structure on the laser tracks and finer cells along the core. EDX analysis (the corresponding point and area scans are not shown here) indicates that the dendrite shaped reinforcement are rich in $\mathrm{Al}, \mathrm{Ti}$, and $\mathrm{Mo}$, corresponding to the $\mathrm{Al}_{6} \mathrm{MoTi}$ phase observed by XRD.

\section{B. Mechanical and tribological properties}

The hardness of the Al-12Si SLM samples is $1.28 \pm$ $0.02 \mathrm{GPa}$, whereas the TNMC exhibits an average value of $2.42 \pm 0.35 \mathrm{GPa}$. The samples were checked for density before the compression tests were carried out. Both the $\mathrm{Al}-12 \mathrm{Si}$ and TNMC samples have a relative density of around $\sim 99.5 \%$ and hence they are considered to be sound for the compression tests. The room temperature compression test results of both $\mathrm{Al}-12 \mathrm{Si}$ and TNMC SLM samples are displayed in Fig. 3. The Al-12Si SLM samples show a yield strength of $283 \pm 3$ $\mathrm{MPa}$ and an ultimate compressive strength of $475 \pm 6 \mathrm{MPa}$. The Al-12Si samples do not break up to $60 \%$ strain; hence, the compression tests were stopped once the ultimate compressive loads are reached. On the other hand, the
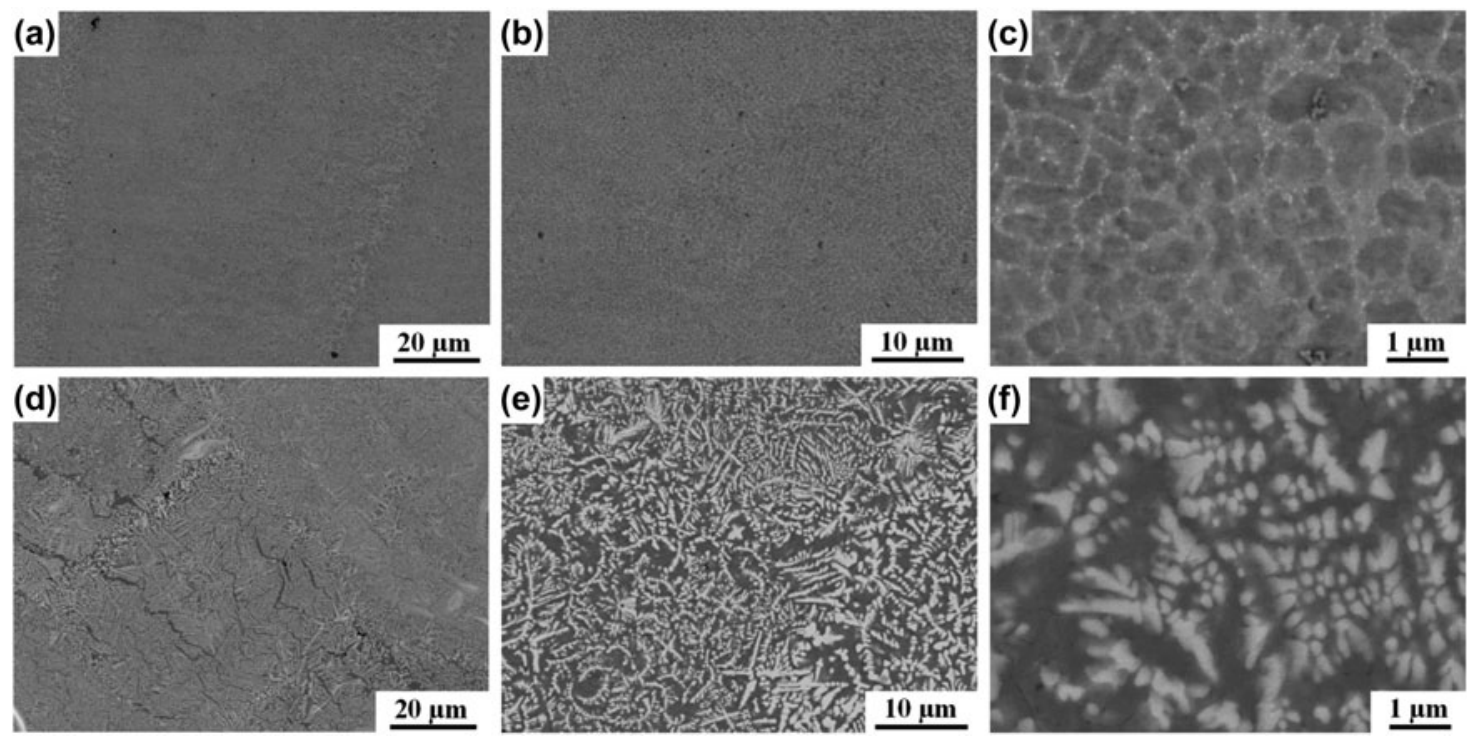

FIG. 2. SEM images showing the microstructure of $(\mathrm{a}-\mathrm{c})$ unreinforced $\mathrm{Al}-12 \mathrm{Si}$ and $(\mathrm{d}-\mathrm{f}) \mathrm{Al}-12 \mathrm{Si}-\mathrm{TNMC}$ produced by SLM. 
TNMC samples exhibit an yield strength of $420 \pm 4 \mathrm{MPa}$ and an ultimate compressive strength of $636 \pm 3 \mathrm{MPa}$. However, the TNMC samples break after $\sim 6 \%$ deformation under compression.

Figure 4(a) furnishes the wear results of both $\mathrm{Al}-12 \mathrm{Si}$ SLM and TNMC samples. At $10 \mathrm{~N}$ load the wear rate of the Al-12Si SLM samples is $\sim 1.31 \times 10^{-12} \mathrm{~m}^{3} / \mathrm{m}$ which is three times higher than the values observed for TNMC $\left(\sim 0.34 \times 10^{-12} \mathrm{~m}^{3} / \mathrm{m}\right)$. This suggests that the Al-12SiTNMCs are more resistant to sliding wear. The composite samples were also tested under different loading conditions varying from 10 to $50 \mathrm{~N}$. With increasing load, the wear rate of the TNMC sample increases from $\sim 0.34 \times 10^{-12} \mathrm{~m}^{3} / \mathrm{m}$ at a load of $10 \mathrm{~N}$ to $\sim 2.08 \times 10^{-12}$ $\mathrm{m}^{3} / \mathrm{m}$ at a load of $50 \mathrm{~N}$. It can also be observed from Fig. 4(a) that the wear resistance follows a negative exponential pattern when the load increases in the sliding wear test. Figure 4(b) shows the normalized wear of the

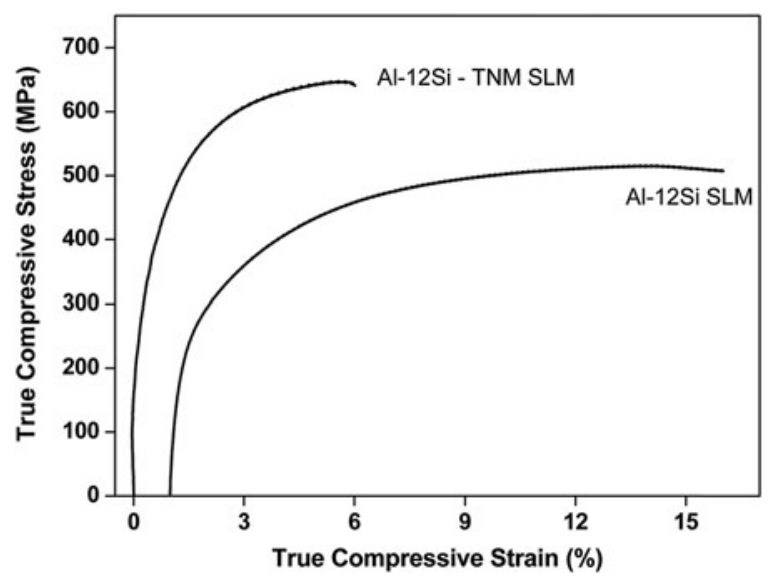

FIG. 3. Compressive room temperature true stress-strain curves of the $\mathrm{Al}-12 \mathrm{Si}$ and $\mathrm{Al}-12 \mathrm{Si}-\mathrm{TNMC}$ samples produced by the SLM process.
TNMC material under different loading conditions as a function of the sliding wear time. As expected, the wear of the composites increases with increasing time for all loads; however, some differences are observed between the wear curves under different loading conditions. The wear curves show a linear pattern for both 10 and $20 \mathrm{~N}$ loads, respectively, whereas the curves are no longer linear when the load increases beyond $20 \mathrm{~N}$. Instead the curves show an irregular wear behavior during the measurement time of $30 \mathrm{~min}$.

The wear scars on the surface of both the $\mathrm{Al}-12 \mathrm{Si}$ and TNMC SLM samples tested at a load of $10 \mathrm{~N}$ are shown in Fig. 5. The arrows in the figures represent the sliding direction. The Al-12Si SLM samples [Figs. 5(a) and 5(b)] show wear scars along the sliding direction, which is typical for a wear surface along with the presence of plowing grooves. It also shows the signs of delamination cracks; however, there is not significant delamination observed except for deep wear scars and plowing. Figure 5(b) also shows the presence of oxides (confirmed using EDX point scan analysis, not shown here). On the other hand, the TNMC SLM sample surface shows wear tracks that are shallow [Figs. 5(c) and 5(d)] compared to the wear scars of the Al-12Si SLM samples. No significant plowing grooves were observed for the TNMC samples. The higher magnification image [Fig. 5(d)] shows the presence of delamination cracks and a partially delaminated layer along with some oxide particles.

Figure 6 presents the wear scars of the TNMC composite samples subjected to different loading conditions $(10,30$, and $50 \mathrm{~N})$. As explained before, the TNMC samples tested at $10 \mathrm{~N}$ load show shallow wear scars and there are no significant plowing besides some cracks and a partially delaminated layer [Figs. 6(a) and 6(b)]. Increasing the load from 10 to $30 \mathrm{~N}$ causes deeper wear scars and plowing grooves [Figs. 6(c) and 6(d)]
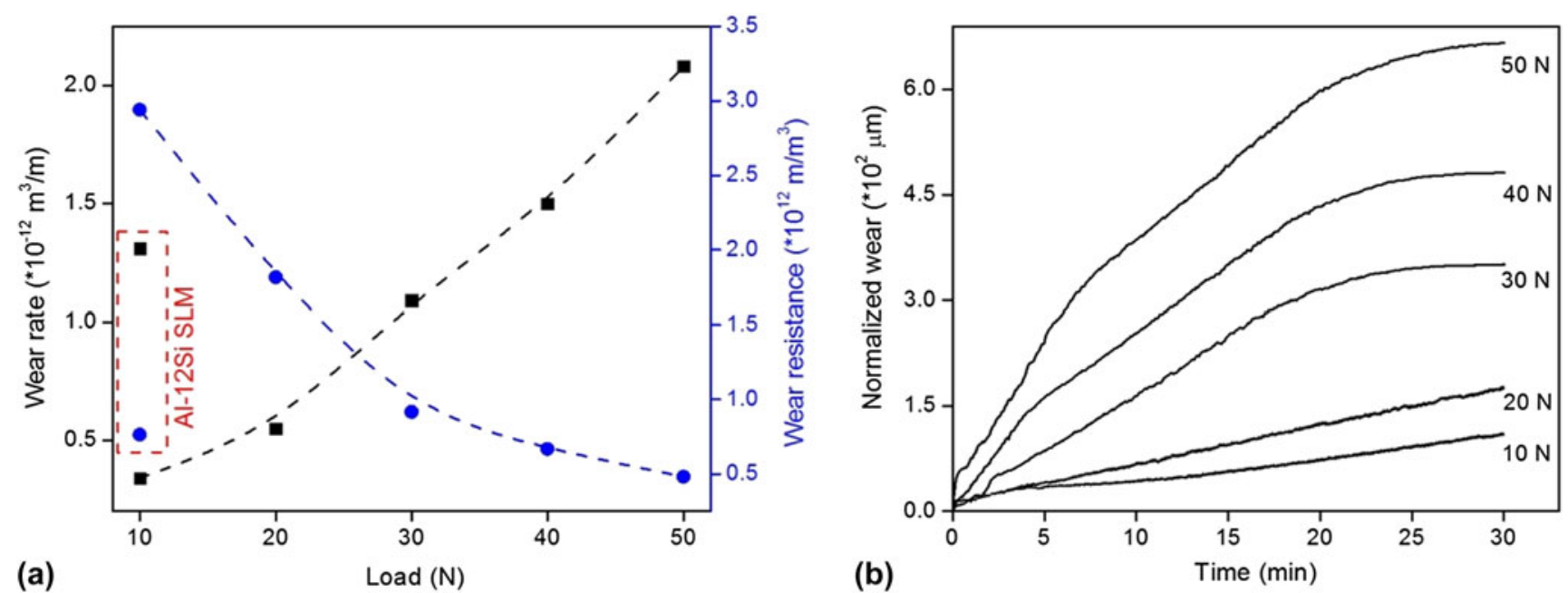

FIG. 4. (a) Wear rate and wear resistance of Al-12Si SLM samples at $10 \mathrm{~N}$ and Al-12Si-TNM SLM composites as a function of different loads from 10 to $50 \mathrm{~N}$. (b) Wear of Al-12Si-TNM SLM composites at different loads (from 10 to $50 \mathrm{~N}$ ) as a function of time. 

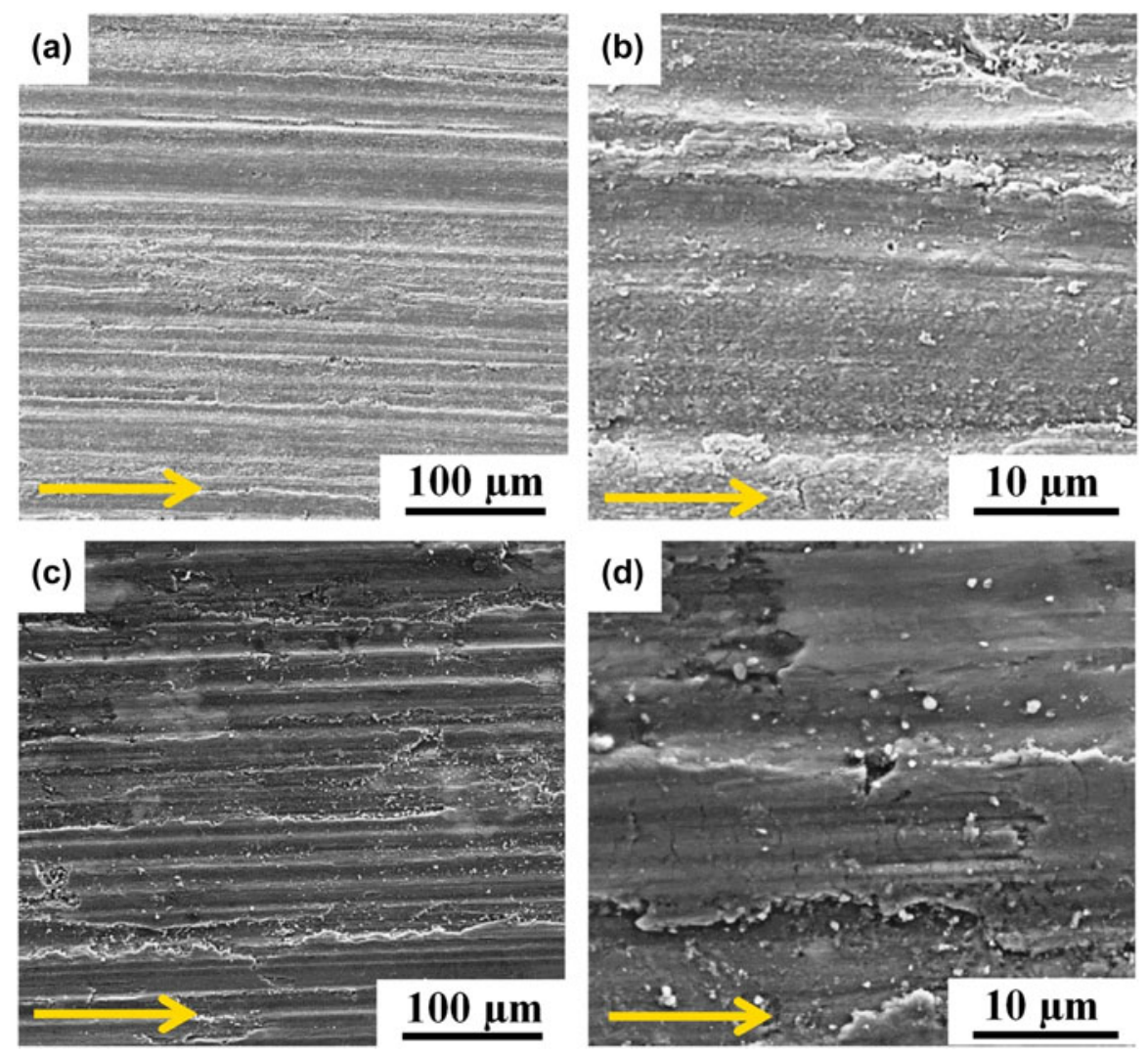

FIG. 5. SEM images showing the wear tracks after sliding wear test for the (a and b) Al-12Si and (c and d) Al-12Si-TNM SLM samples.

compared to the wear scars of the sample tested at $10 \mathrm{~N}$. The wear surface seems to be nonhomogeneous with regions of both deep wear tracks and shallow wear tracks. Also, delamination cracks and subcracks are observed in Fig. 6(d) along with oxide particles. With further increase of the load to $50 \mathrm{~N}$, the nonhomogeneity in the wear surface increases with deeper wear scars in some selected regions and shallow wear tracks in the other regions [Figs. 6(e) and 6(f)]. Delamination of the layer along with particle pullout can be observed from Fig. 6(f) along with the presence of delamination cracks and selective oxidation.

\section{DISCUSSION}

\section{A. Phase formation}

A detailed characterization of the Al-12Si SLM samples can be found elsewhere. ${ }^{14}$ Hence, only requisite information about the Al-12Si SLM samples is presented here to have a comparison with that of the TNMC samples. The XRD patterns of the Al-12Si GAP and SLM samples do not show distinct peaks of $\mathrm{Si}$, which may be attributed to the large degree of supersaturation of $\mathrm{Si}$ in $\mathrm{Al} .{ }^{14}$ The lattice parameter of $\alpha-\mathrm{Al}$, evaluated using the Rietveld profile refinement method ${ }^{49}$ is 0.40513 and $0.40508 \mathrm{~nm}$ for $\mathrm{Al}-12 \mathrm{Si}$ GAP and SLM samples, respectively. This confirms the formation of a supersaturated solid solution of $\mathrm{Si}$ in $\mathrm{Al}$ and the amount of free residual $\mathrm{Si}$ in these samples is less than $1 \mathrm{wt} \% .^{14}$ Moreover, the $\alpha$-Al peaks are broader in the SLM samples, which are correlated with a fine crystallite size $(118 \pm 3 \mathrm{~nm}$ for the SLM sample and $136 \pm 5 \mathrm{~nm}$ for the GAP powder). The reversal of the peak intensities between the (111) and (200) peaks of $\alpha$-Al in the $\mathrm{Al}-12 \mathrm{Si}$ SLM samples points to the development of the texture in the SLM material. ${ }^{14}$ The TNMC SLM samples exhibit a lattice parameter of $0.40511 \mathrm{~nm}$ for $\alpha$-Al, which is different from the lattice parameter of $\alpha$-Al observed in the Al-12Si SLM samples. This marginal lattice parameter increase can be ascribed to a smaller amount of $\mathrm{Si}$ in $\alpha$-Al. However, the amount of free residual $\mathrm{Si}$ is calculated to be $\sim 1 \mathrm{wt} \%$, which is similar to that of the $\mathrm{Al}-12 \mathrm{Si}$ SLM samples.

The TNMC samples show the presence of the $\mathrm{Al}_{6} \mathrm{MoTi}$ phase but no hints for the formation of $\mathrm{TiAl}_{3}$ and $\mathrm{MoNb}$ phases suggesting a phase transformation from $\mathrm{TiAl}_{3}$ and $\mathrm{MoNb}$ to $\mathrm{Al}_{6} \mathrm{MoTi}$ in the presence of the Al-12Si matrix. A similar phase transformation sequence has been observed for the $\mathrm{Ti}-\mathrm{Al}$ alloys subjected to intense ion beam irradiation, ${ }^{50}$ where Mingjuan et al. observed changes in the local composition of the melt, whereby an increase in the chemical concentration of $\mathrm{Al}$ 

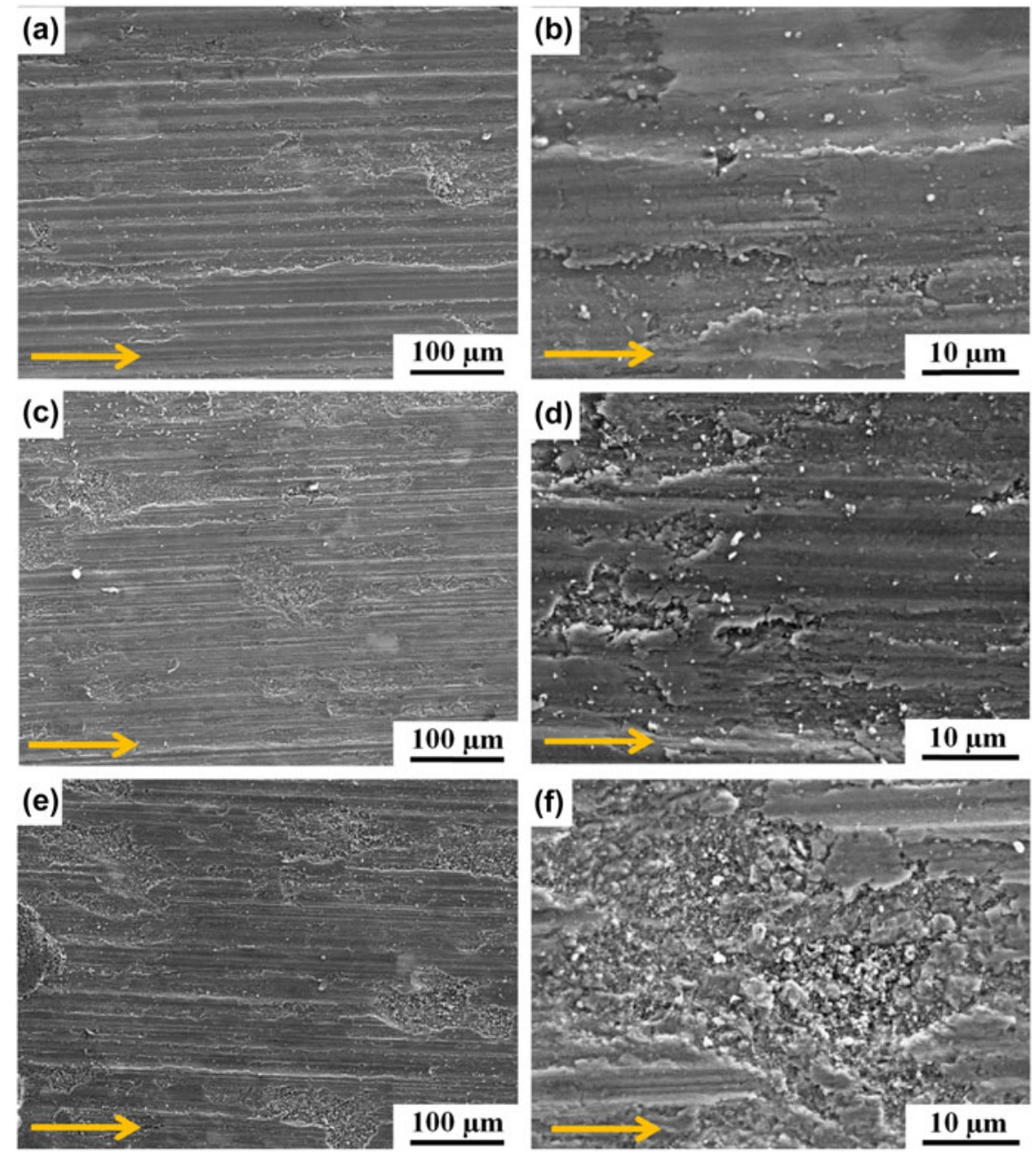

FIG. 6. SEM images of the wear tracks after sliding wear test for the Al-12Si-TNMCs as a function of load (a and b) $10 \mathrm{~N}$, (c and d) $30 \mathrm{~N}$ and (e and f) $50 \mathrm{~N}$.

and Mo and a decrease in the Ti concentration lead to the formation of the $\mathrm{Al}_{6} \mathrm{MoTi}$ phase, making this phase thermodynamically stable. ${ }^{50}$

By considering the increase in the lattice parameter of $\alpha-\mathrm{Al}$ and the formation of the $\mathrm{Al}_{6} \mathrm{MoTi}$ phase, the following scenario can be proposed. During SLM of the TNMC composites, both the $\mathrm{Al}-12 \mathrm{Si}$ and TNM powders are expected to melt due to the high energy density of $\sim 55 \mathrm{~J} / \mathrm{mm}^{3}$, which is applied for producing a defect free sample. The degree of constitutional undercooling increases under high energy input, which leads to the formation of a supersaturated solid solution. In the present melt, the $\mathrm{Si}$ from $\mathrm{Al}-12 \mathrm{Si}$ contributes to form a supersaturated solid solution of $\mathrm{Al}^{51}{ }^{51}$ However, having a similar amount of free residual $\mathrm{Si}$ in both the TNMC SLM and Al-12Si SLM samples and considering the formation of the $\mathrm{Al}_{6} \mathrm{MoTi}$ phase, it can be postulated that the melt becomes deficient in Ti due to the diffusion of some Ti into Al. Also, it is believed that during the laser melting process, mixing of the melt takes place due to the convection phenomena. It has been reported that the convection pattern of the fluid flow during the laser melting process is directed radially outward with the formation of symmetric vortices on the cross-section of the melt pool. ${ }^{52}$ Such through mixing of the melt pool facilitates $\mathrm{Ti}$ to be in contact with $\mathrm{Al}$ and the high degree of constitutional undercooling results in the formation of a supersaturated solid solution of both $\mathrm{Ti}$ and $\mathrm{Si}$ in $\mathrm{Al}$ $\left(\mathrm{Al}_{\mathrm{SS}-\mathrm{Si}-\mathrm{Ti}}\right)$ as demonstrated in Fig. 7. Such a reaction will consume $\mathrm{Ti}$ from the $\mathrm{TiAl}_{3}$ phase and the deficiency in $\mathrm{Ti}$ will lead to the formation of the $\mathrm{Al}_{6} \mathrm{MoTi}$ intermetallic phase.

\section{B. Mechanical properties and wear mechanism}

The Vickers microhardness of the TNMC SLM samples shows a greater deviation from the average hardness $(0.35 \mathrm{GPa})$ as compared to the Al12-Si SLM samples $(0.02 \mathrm{GPa})$ due to the significant difference in the hardness between the two phases $\mathrm{Al}_{\mathrm{SS}-\mathrm{Si}-\mathrm{Ti}}$ and $\mathrm{Al}_{6} \mathrm{MoTi}$ 
observed in the TNMC composites. The hardness of the $\mathrm{Al}_{\mathrm{SS}-\mathrm{Si}-\mathrm{Ti}}$ phase is $1.62 \pm 0.03 \mathrm{GPa}$ and $\mathrm{Al}_{6} \mathrm{MoTi}$ exhibits a hardness of $3.95 \pm 0.02 \mathrm{GPa}$, which is similar to TiAl produced by electron beam melting. ${ }^{53}$ Such high strength reinforcement helps to increase the hardness of the composite significantly. The TNMC samples show yield and ultimate compressive strengths, which are $\sim 140$ and $\sim 160 \mathrm{MPa}$, respectively, higher than the corresponding values of the Al-12Si SLM samples. On the other hand, the TNMC samples break at $\sim 6 \%$ total strain under compressive deformation, whereas the Al-12Si SLM samples do not fracture until $60 \%$ of deformation. This shows that the TNM reinforcement helps to improve the strength of the composite but renders the composites extremely brittle.

During the sliding wear tests, the counter surface may induce a high strain level at the contact surface of the sample. ${ }^{54}$ Such a high strain level will eventually lead to cracks and subsurface cracks, as observed for the Al-12Si SLM samples. However, these cracks are not deep enough for delamination due to the resistance exerted by the sample surface. Also, the sliding of the sample against a counter disc causes a strong temperature rise along the sample surface as well as on the counter disc. The temperature rise leads to preferential oxidation of the sample surface (as observed by EDX analysis, not shown here). ${ }^{55,56}$ Hence, the wear of Al-12Si SLM samples takes place through plowing, partial delamination and oxidative wear. ${ }^{56-58}$ This scenario also holds for the Al-12Si-TNMCs. On the other hand, the Al-12SiTNMCs are prepared by SLM at $10 \mathrm{~N}$ wear and also through partial delamination. The wear rate remains linear up to a testing time of $30 \mathrm{~min}$. When the load increases from 10 to $30 \mathrm{~N}$ and beyond, the wear rate seems to have

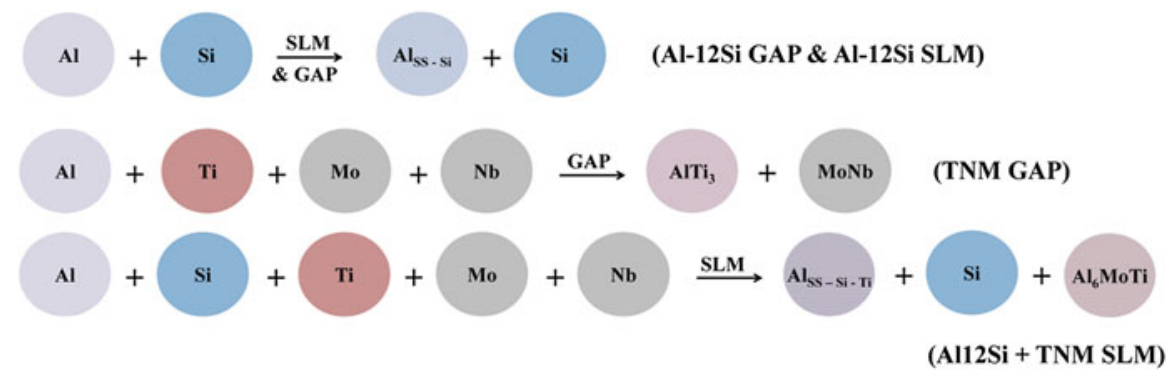

FIG. 7. Schematics illustrating the formation of supersaturated solid solution of $\mathrm{Si}$ in $\mathrm{Al}$ and $\mathrm{Ti}$ and $\mathrm{Si}$ in $\mathrm{Al}$ for Al-12Si SLM and Al-12Si-TNM SLM composites.
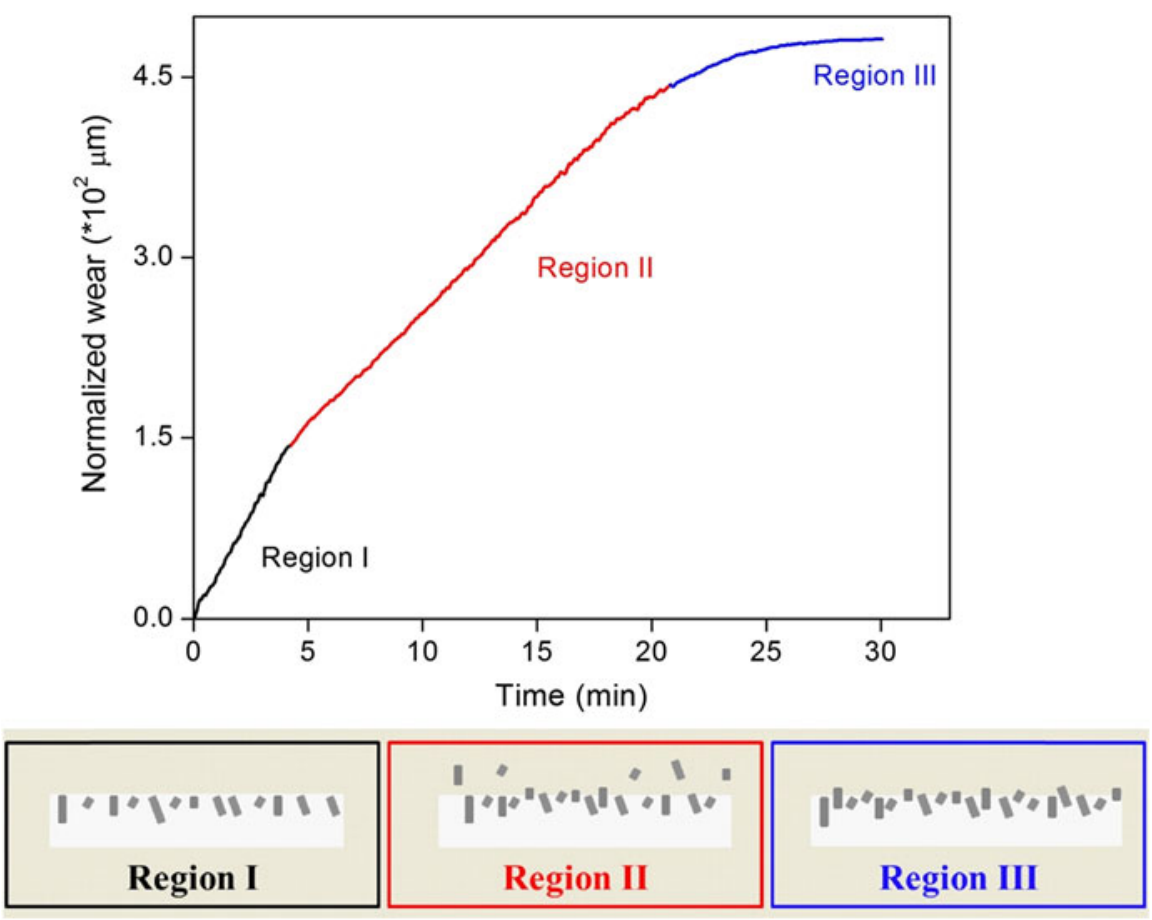

FIG. 8. Plot showing the three different rates of wear observed during the wear of the Al-12Si-TNM SLM composites at $40 \mathrm{~N}$ loads as a function of time and schematics illustrating the mode of wear taking place in the three regions. 
a different behavior in the $30 \mathrm{~min}$ testing time regime [Fig. 4(b)]. The samples experience a maximum wear rate for the initial $\sim 5 \mathrm{~min}$ and with increasing time, the wear takes place at a decreased rate (up to $\sim 20 \mathrm{~min}$ ). With further increasing time, the wear rate decreases. This might as well be correlated with the nonuniform wear surfaces observed in Figs. 6(c)-6(f).

Based on the microstructure of the Al-12Si-TNMCs, the wear rate data (Fig. 4) and the wear scar images (Fig. 6), the following wear mechanism can be proposed. The surface of the composites consists of $\mathrm{Al}_{\mathrm{SS}-\mathrm{Si}-\mathrm{Ti}}$ and $\mathrm{Al}_{6} \mathrm{MoTi}$ phases. As already discussed, the $\mathrm{Al}{ }_{\mathrm{SS}-\mathrm{Si}-\mathrm{Ti}}$ phase has a hardness of $1.62 \pm 0.03 \mathrm{GPa}$, whereas a hardness of $3.95 \pm 0.02 \mathrm{GPa}$ was found for the $\mathrm{Al}_{6} \mathrm{MoTi}$ intermetallic phase. During wear, the soft $\mathrm{Al}_{\mathrm{SS}-\mathrm{Si}-\mathrm{Ti}}$ gets worn out of the surface (marks of plowing) and the $\mathrm{Al}_{6} \mathrm{MoTi}$ intermetallic phase contributes to its resistance (which is termed as Region I-Fig. 8). At the initial stages $(<5 \mathrm{~min})$ both the $\mathrm{Al}_{\mathrm{SS}-\mathrm{Si}-\mathrm{Ti}}$ and $\mathrm{Al}_{6} \mathrm{MoTi}$ phases are in contact with the counter disc causing the sliding wear. With increasing time, as the $\mathrm{Al}_{\mathrm{SS}-\mathrm{Si}-\mathrm{Ti}}$ phase wears out, the amount of $\mathrm{Al}_{6} \mathrm{MoTi}$ along the surface increases and it decelerates the wear rate. Once the $\mathrm{Al}_{6} \mathrm{MoTi}$ phase is devoid of the surrounding soft $\mathrm{Al}_{\mathrm{SS}-\mathrm{Si}-\mathrm{Ti}}$ phase, the pull out of the $\mathrm{Al}_{6} \mathrm{MoTi}$ particles is inevitable as illustrated in Fig. 8. In this phase (Region II), the wear rate is influenced by both the $\mathrm{Al}_{\mathrm{SS}-\mathrm{Si}-\mathrm{Ti}}$ and $\mathrm{Al}_{6} \mathrm{MoTi}$ phases. The $\mathrm{Al}_{\mathrm{SS}-\mathrm{Si}-\mathrm{Ti}}$ phase contributes to the wear in the form of plowing (and partial delamination) and the pull out of the $\mathrm{Al}_{6} \mathrm{MoTi}$ phase also takes place simultaneously. With increasing time, the amount of $\mathrm{Al}_{\mathrm{SS}-\mathrm{Si}-\mathrm{Ti}}$ phase which is in contact with the counter disc drops significantly and as the amount of $\mathrm{Al}_{6} \mathrm{MoTi}$ phase further increases, thus reducing the wear rate more (Region III).

\section{SUMMARY}

Al-12Si (80 vol\%)-TNM composites were successfully prepared by the SLM process. Structural and microstructural characterization reveals chemical reactions between the matrix and the reinforcement leading to the formation of $\mathrm{Al}_{\mathrm{SS}-\mathrm{Si}-\mathrm{Ti}}$ and $\mathrm{Al}_{6} \mathrm{MoTi}$ phases. The formation of the $\mathrm{Al}_{6} \mathrm{MoTi}$ phase is promoted by the devoid of $\mathrm{Ti}$ in the melt, which is due to the supersaturation of $\mathrm{Al}$ with $\mathrm{Ti}$. The compression test results show that the composites have improved strength levels compared with the Al-12Si matrix. However, the composites are less plastically deformable and break at $\sim 6 \%$ total strain under compression. The composite also show an improved wear resistance compared with the unreinforced matrix and exhibit similar wear mechanisms. However, the surface of the composite at higher loads shows uniform wear scars which might be due to partial delamination that occurred from particle pull out. The wear rate of the composites increases with increasing load from 10 to $50 \mathrm{~N}$. At lower loads (10 and $20 \mathrm{~N})$, the composites show uniform wear throughout the $30 \mathrm{~min}$ test time. When the load increases beyond $30 \mathrm{~N}$, nonuniform wear rates are found for the composites. The maximum wear rate is observed at the early stages and it decreases after $5 \mathrm{~min}$ of continuous sliding. The results demonstrate that composites with metallic reinforcement and superior properties can be processed using the SLM process.

\section{ACKNOWLEDGMENTS}

The authors thank Harald Merker for technical assistance. P. Wang would like to acknowledge the fellowship support from the China Scholarship council.

\section{REFERENCES}

1. H. Attar, K.G. Prashanth, A.K. Chaubey, M. Calin, L.C. Zhang, S. Scudino, and J. Eckert: Comparison of wear properties of commercially pure titanium prepared by selective laser melting and casting processes. Mater. Lett. 142, 38 (2015).

2. S. Scudino, C. Unterdörfer, K.G. Prashanth, H. Attar, N. Ellendt, V. Unhelwinkel, and J. Eckert: Additive manufacturing of $\mathrm{Cu}-$ 10Sn bronze. Mater. Lett. 156, 202 (2015).

3. K.G. Prashanth, H. Shakur Shahabi, H. Attar, V.C. Srivastava, N. Ellendt, V. Uhlenwinkel, J. Eckert, and S. Scudino: Production of high strength $\mathrm{Al}_{85} \mathrm{Nd}_{8} \mathrm{Ni}_{5} \mathrm{Co}_{2}$ alloy by selective laser melting. Addit. Manuf. 6, 1 (2015).

4. S. Bremen, W. Meiners, and A. Diatlov: Selective laser melting: A manufacturing technology for the future? Laser Tech. J. 9, 33 (2012).

5. T.B. Sercombe and G.B. Schaffer: Rapid manufacturing of aluminum components. Science 301, 1225 (2023).

6. H. Attar, L. Löber, A. Funk, M. Calin, L.C. Zhang, K.G. Prashanth, S. Scudino, Y.S. Zhang, and J. Eckert: Mechanical behavior of porous commercially pure $\mathrm{Ti}$ and $\mathrm{Ti}-\mathrm{TiB}$ composite materials manufactured by selective laser melting. Mater. Sci. Eng., A $\mathbf{6 2 5}$, 350 (2015).

7. C.L. Qiu, S. Yue, N.J.E. Adkins, M. Ward, H. Hassanin, P.D. Lee, P.J. Withers, and M.M. Attallah: Influence of processing conditions on strut structure and compressive properties of cellular lattice structures fabricated by selective laser melting. Mater. Sci. Eng., A 628, 188 (2015).

8. L. Löber, F.P. Schimansky, U. Kühn, F. Pyczak, and J. Eckert: Selective laser melting of a beta-solidifying TNM-B1 titanium aluminide alloy. J. Mater. Process. Technol. 214, 1852 (2014).

9. E.O. Olakanmi, R.F. Cochrane, and K.W. Dalgarno: A review on selective laser sintering/melting (SLS/SLM) of aluminium alloy powders: Processing, microstructure, and properties. Prog. Mater. Sci. 74, 401 (2015), doi: 10.1016/j.pmatsci.2015.03.002

10. M.M. Ma, Z.M. Wang, M. Gao, and X.Y. Zeng: Layer thickness dependence of performance in high-power selective laser melting of $1 \mathrm{Cr} 18 \mathrm{Ni}$ Ti stainless steel. J. Mater. Process. Technol. 215 , 142 (2015).

11. G. Casalino, S.L. Campanelli, N. Countuzzi, and A.D. Ludovico: Experimental investigation and statistical optimization of the selective laser melting process of a maraging steel. Opt. Laser Technol. 65, 151 (2015).

12. R. Li, Y.S. Shi, Z.G. Wang, L. Wang, J.H. Liu, and W. Jiang: Densification behavior of gas and water atomized $316 \mathrm{~L}$ stainless steel powder during selective laser melting. Appl. Surf. Sci. 13, 4350 (2010). 
13. B.C. Zhang, L. Dembinski, and C. Coddet: The study of the laser parameters and environment variables effect on mechanical properties of high compact parts elaborated by selective laser melting of 316L powder. Mater. Sci. Eng., A 584, 21 (2013).

14. K.G. Prashanth, S. Scudino, H.J. Klauss, K.B. Surreddi, L. Löber, Z. Wang, A.K. Chaubey, U. Kühn, and J. Eckert: Microstructure and mechanical properties of Al-12Si produced by selective laser melting: Effect of heat treatment. Mater. Sci. Eng., A 590, 153 (2014).

15. K.G. Prashanth, B. Debalina, Z. Wang, P.F. Gostin, A. Gebert, M. Calin, U. Kühn, M. Kamaraj, S. Scudino, and J. Eckert: Tribological and corrosion properties of $\mathrm{Al}-12 \mathrm{Si}$ produced by selective laser melting. J. Mater. Res. 29, 2044 (2014).

16. L. Thijs, K. Kempen, J-P. Kruth, and J. Van Humbeeck: Finestructured aluminium products with controllable texture by selective laser melting of pre-alloyed $\mathrm{AlSi} 10 \mathrm{Mg}$ powder. Acta Mater. 61, 1809 (2013).

17. D.D. Gu, Y-C. Hagedorn, W. Meiners, G.B. Meng, R.J.S. Batista, K. Wissenbach, and R. Poprawe: Densification behavior, microstructure evolution, and wear performance of selective laser melting processed commercially pure titanium. Acta Mater. 60, 3849 (2012).

18. N. Otawa, T. Sumida, H. Kitagaki, K. Sasaki, S. Fujibayashi, M. Takemoto, T. Nakamura, T. Yamada, Y. More, and T. Matsushita: Custom-made titanium devices as membranes for bone augmentation in implant treatment: Modeling accuracy of titanium products constructed with selective laser melting. J. Cranio Maxill. Surg. 43, 1289 (2015).

19. S. Leuders, M. Thöne, A. Riemer, T. Niendorf, T. Tröster, H.A. Richard, and H.J. Maier: On the mechanical behavior of titanium alloy Ti6Al4V manufactured by selective laser melting: Fatigue resistance and crack growth performance. Int. J. Fatigue 48, 300 (2013).

20. B. Vrancken, L. Thijs, J-P. Kruth, and J. Van Humbeeck: Microstructure and mechanical properties of a novel $\beta$ titanium metallic composite by selective laser melting. Acta Mater. 68, 150 (2014).

21. K.N. Amato, S.M. Gaytan, L.E. Murr, E. Martinez, P.W. Shindo, J. Hernandez, S. Collins, and F. Medina: Microstructures and mechanical behavior of Inconel 718 fabricated by selective laser melting. Acta Mater. 60, 2229 (2012).

22. T. Vilaro, C. Colin, J.D. Bartout, L. Naze, and M. Sennour: Microstructural and mechanical approaches of the selective laser melting process applied to a nickel-base superalloy. Mater. Sci. Eng., A 534, 446 (2012).

23. I. Shishkovsky, I. Yadroitsev, and I. Smurov: Direct selective laser melting of nitinol powder. Phys. Procedia 39, 447 (2012).

24. K.A. Mumtaz, P. Erasenthiran, and N. Hopkinson: High density selective laser melting of waspaloy. J. Mater. Process Technol. 195, 77 (2008)

25. Y.S. Hedberg, B. Qian, Z.J. Shen, S. Virtanen, and I.O. Wallinder: In vitro biocompatibility of CoCrMo dental alloys fabricated by selective laser melting. Dent. Mater. 30, 525 (2014)

26. X. Zhou, K.L. Li, D.D. Zhang, X.H. Liu, J. Ma, W. Liu, and Z.J. Shen: Textures formed in a CoCrMo alloy by selective laser melting. J. Alloys Compd. 631, 153 (2015).

27. B. Song, S.J. Dong, P. Coddet, G.S. Zhou, S. Ouyang, H.L. Liao, and C. Coddet: Microstructure and tensile behavior of hybrid nano-micro $\mathrm{SiC}$ reinforced iron matrix composites produced by selective laser melting. J. Alloys Compd. 579, 415 (2013).

28. L. Hao, S. Dadbakhsh, O. Seaman, and M. Felstead: Selective laser melting of a stainless steel and hydroxyapatite composite for load-bearing implant development. J. Mater. Process. Technol. 209, 5793 (2009).

29. Q.S. Wei, S. Li, C.J. Han, W. Li, H. Cheng, L. Hao, and Z.S. Shi: Selective laser melting of stainless-stell/nano-hydroxyapatite composites for medical applications: Microstructure, element distribution and mechanical properties. J. Mater. Process. Technol. 222, 444 (2015).

30. H. Attar, M. Bönisch, M. Calin, L.C. Zhang, S. Scudino, and J. Eckert: Selective laser melting of in situ titanium-titanium boride composites: Processing, microstructure and mechanical properties. Acta Mater. 76, 13 (2014).

31. D.D. Gu, Z.Y. Wang, Z. Shen, Q. Lin, and Z.F. Li: In-situ TiC particle reinforced Ti-Al matrix composites: Powder preparation by mechanical alloying and selective laser melting behavior. Appl. Surf. Sci. 255, 9230 (2009).

32. D.D. Gu, Z.C. Hagedorn, W. Meiners, K. Wissenbach, and R. Poprawe: Selective laser melting of in-situ TiC/Ti5Si3 composites with novel reinforcement architecture and elevated performance. Surf. Coat. Technol. 205, 3285 (2011).

33. P. Krakhmalev and I. Yadroitsev: Microstructure and properties of intermetallic composite coatings fabricated by selective laser melting of $\mathrm{Ti}-\mathrm{SiC}$ powder mixtures. Intermetallics 46, 147 (2014).

34. F. Chang, D.D. Gu, D.H. Dai, and P.P. Yuan: Selective laser melting of in situ Al4SiC4 $+\mathrm{SiC}$ hybrid reinforced Al matrix composites: Influence of starting $\mathrm{SiC}$ particle size. Surf. Coat. Technol. 272, 15 (2015).

35. D.D. Gu, H.Q. Wang, F. Chang, D.H. Dai, P.P. Yuan, Z.X. Hagedorn, and W. Meiners: Selective laser melting additive manufacturing of $\mathrm{TiC} /$ AlSi10Mg bulk-form nanocomposites with tailored microstructures and properties. Phys. Procedia 56, 108 (2014).

36. S. Dadbakhsh, L. Hao, P.G.E. Jerrard, and D.Z. Zhang: Experimental investigation on selective laser melting behavior and processing windows on in situ reacted $\mathrm{Al} / \mathrm{Fe}_{2} \mathrm{O}_{3}$ powder mixture. Powder Technol. 231, 112 (2012).

37. Z. Wang, K.G. Prashanth, A.K. Cahubey, L. Löber, F.P. Schimansky, F. Pyczak, W.W. Zhang, S. Scudino, and J. Eckert: Tensile properties of Al-12Si matrix composites reinforced with Ti-Al based particles. J. Alloys Compd. 630, 256 (2015).

38. R. Gerling, H. Clemens, and F.P. Schimansky: Powder metallurgical processing of intermetallic gamma titanium aluminides. $A d v$. Eng. Mater. 6, 23 (2004).

39. H. Attar, K.G. Prashanth, L.C. Zhang, M. Calin, I.V. Okulov, S. Scudino, C. Yang, and J. Eckert: Effect of powder particle shape on the properties of in situ Ti-TiB composite materials produced by selective laser melting. J. Mater. Sci. Technol. 31, 1001 (2015), doi: 10.1016/j.jmst.2015.08.007.

40. K.G. Prashanth, S. Kumar, S. Scudino, B.S. Murty, and J. Eckert: Fabrication and response of $\mathrm{Al}_{70} \mathrm{Y}_{16} \mathrm{Ni}_{10} \mathrm{Co}_{4}$ glass reinforced metal matrix composites. Mater. Manuf. Processes 26, 1242 (2011).

41. J.F. Archad: Contact and rubbing of flat surface. J. Appl. Phys. 24, 981 (1953)

42. Z. Wang, K.G. Prashanth, S. Scudino, J. He, W.W. Zhang, Y.Y. Li, M. Stoica, G. Vaughan, D.J. Sordelet, and J. Eckert: Effect of ball milling on structure and thermal stability of A184Gd6Ni7Co3 glassy powders. Intermetallics 46, 97 (2014).

43. B. Huneau, P. Rogl, K. Zeng, R. Schmid-Fetzer, M. Bohn, and J. Bauer: The ternary system Al-Ti-Ni part I: Isothermal section at $900^{\circ} \mathrm{C}$, Experimental investigation and thermodynamic calculation. Intermetallics 7, 1337 (1999).

44. http://resource.npl.co.uk/mtdata/phdiagrams/monb.htm binary phase diagram).

45. L.D. Gulay, M. Daszkiewicz, and V.Y. Shemat: Crystal structure of the $\mathrm{RE}_{2} \mathrm{PbS}_{4}(\mathrm{RE}=\mathrm{Y}$, Dy, Ho, Er, and Tm) compounds and a comparison with the crystal structures of the other rare earth lead chalcogenides. Z. Anorg. Allg. Chem. 634, 1887 (2005).

46. H. Schwab, K.G. Prashanth, L. Löber, U. Kühn, and J. Eckert: Selective laser melting of Ti-45Nb alloy. Metals 5, 686 (2015). 
47. P. Ma, K.G. Prashanth, S. Scudino, Y.D. Jia, H.W. Wang, C.M. Zou, Z.J. Wei, and J. Eckert: Influence of annealing on mechanical properties of Al-20Si processed by selective laser melting. Metals 4, 28 (2014).

48. X.P. Li, X.J. Wang, M. Saunders, A. Suvorova, L.C. Zhang, Z.J. Liu, M.H. Fang, Z.H. Huang, and T.B. Sercombe: A selective laser melting and solution heat treatment refined Al-12Si alloy with a controllable ultrafine eutectic microstructure and $25 \%$ tensile ductility. Acta Mater. 95, 74 (2015).

49. H.M. Rietveld: A profile refinement method for nuclear and magnetic structures. J Appl. Crystallogr. 2, 65 (1969).

50. L. Mingjuan, G. Qingye, and L. Weibo: Study on the surface phase transformation of Ti based alloy irradiated by intense pulsed ion beams. J. Radiat. Res. Radiat. Process. 28, 79 (2010).

51. K.G. Prashanth, R. Damodaram, S. Scudino, Z. Wang, K. Prasad Rao, and J. Eckert: Friction welding of Al-12Si parts produced by selective laser melting. Mater. Des. 57, 632 (2014).
52. P.P. Yuan, D.D. Gu, and D.H. Dai: Particulate migration behavior and its mechanism during selective laser melting of TiC reinforced Al matrix nanocomposites. Mater. Des. 82, 46 (2015), doi: 10.1016/j.matdes.2015.05.041.

53. L.E. Murr, S.M. Gaytan, A. Ceylan, E. Martinez, J.L. Martinez, D.H. Hernandez, B.I. Machado, D.A. Ramirez, F. Medina, S. Collins, and R.B. Wicker: Characterization of titanium aluminide alloy components fabricated by additive manufacturing using electron beam melting. Acta Mater. 58, 1887 (2010).

54. N.P. Suh: The delamination theory of wear. Wear 25, 111 (1973)

55. D.K. Dwivedi: Adhesive wear behavior of cast aluminium-silicon alloys: Overview. Mater. Des. 31, 2517 (2010).

56. Y. Liu, R. Asthana, and P.A. Rohatgi: Map for wear mechanisms in aluminium alloys. J. Mater. Sci. 26, 99 (1991).

57. C. Subramanian: Some considerations towards the design of a wear resistant aluminium alloy. Wear 155, 193 (1992).

58. J. Zhang and A.T. Alpas: Transition between mild and severe wear in aluminium alloys. Acta Mater. 45, 513 (1997). 